\title{
USO DE ÁCIDO GIBERÉLICO EM SEMENTES DE FRUTA-DO-CONDE (Annona squamosa L.) VISANDO À PRODUÇÃO DE MUDAS EM DIFERENTES EMBALAGENS ${ }^{1}$
}

\author{
GISELA FERREIRA ${ }^{2}$, PAULO ROBERTO ERIG ${ }^{3}$, EDEMAR MORO $^{4}$
}

\begin{abstract}
RESUMO - O presente trabalho foi conduzido no laboratório de sementes e casa de vegetação da UNIOESTE - Câmpus de Marechal Cândido Rondon - PR, com o objetivo de avaliar o efeito de diferentes concentrações de ácido giberélico $\left(\mathrm{GA}_{3}\right)$ na germinação de sementes e na emergência de plântulas de fruta-do-conde (Annona squamosa L.), em diferentes recipientes, visando à produção de mudas. O experimento foi instalado em delineamento experimental inteiramente casualizado. Os tratamentos foram compostos pela embebição das sementes em sete concentrações de ácido giberélico $\left(0 ; 50 ; 100 ; 250 ; 500 ; 750\right.$ e 1000 mg. $\left.\mathrm{L}^{-1}\right)$, por 5 horas, com 4 repetições de 25 sementes. No campo, os tratamentos foram constituídos das sete concentrações de $\mathrm{GA}_{3}$ e dois tipos de embalagens (bandejas de isopor e sacolas de polietileno), com 4 repetições de 25 sementes. As avaliações do laboratório constaram de porcentagem total de sementes germinadas, dormentes e mortas; porcentagem total de plântulas normais e anormais, e índice de velocidade de germinação (IVG) e do campo, pela porcentagem total de plântulas emergidas; índice de velocidade de emergência de plântulas (IVE); altura de plântulas e número de folhas. Os dados foram submetidos à análise de variância e as médias comparadas pelo teste de Tukey, a 5\% de probabilidade. Verificou-se que o $\mathrm{GA}_{3}$ promoveu o incremento na germinação de sementes de Annona squamosa e que as sacolas de polietileno foram mais adequadas do que as bandejas no desenvolvimento das plântulas na fase inicial.
\end{abstract}

Termos de indexação: fitorreguladores, produção de mudas, fruta-do-conde, Annona squamosa L.

\section{GIBERELLIC ACID USE ON SUGAR APPLE (Annona squamosa L.) SEEDS AIMING SEEDLING PRODUCTION IN DIFFERENT PACKS.}

\begin{abstract}
The objetive of this experiment, was to evaluate the effect of giberellic acid $\left(\mathrm{GA}_{3}\right)$ concentrations, on sugar apple (Annona squamosa L.) seeds germination and seedlings emergence. The experiment was carried out in a completely randomized design. The treatments were composed of seeds soaking in $7 \mathrm{GA}_{3}$ concentrations $\left(0,50,100,250,500,750\right.$ and $1.000 \mathrm{mg} \cdot \mathrm{L}^{-1}$ of GA $)$, for 5 hours, with 4 replicates of 25 seeds, and kept at germination chamber. In greenhouse condition, the treatments were composed of the $7 \mathrm{GA}_{3}$ concentrations and 2 types of packs (styrofoam trays and black polyethylene bags), with 4 replicates of 25 seeds. The evaluations performed at the laboratory consisted of the total percentage of germinated seeds, dormant and dead seeds; total percentage of normal and abnormal seedlings; and germination speed index. The evaluations done at greenhouse conditions consisted of the total percentage of seedlings emergence; emergence speed index; plants height and number of leaves. The datas were subjected to variance analysis and the averages compared by the Tukey test, with $5 \%$ probability. The results obtained, suggested that $\mathrm{GA}_{3}$ promoted the increase of the germination of Annona squamosa seeds, and that the black polyethylene bags have been the most adequate for the seedlings development.
\end{abstract}

Index terms: plant regulator, seedlings, sugar apple, Annona squamosa L.

\section{INTRODUÇÃO}

A fruta-do-conde (Annona squamosa L.), conhecida regionalmente por diversos nomes como ata, pinha e anona, tem despertado interesse de produtores de várias regiões desde a década de oitenta. A cultura é, basicamente, propagada por sementes e a enxertia é utilizada para multiplicação de clones mais produtivos. Porém, a produção de mudas por via sexuada esbarra na dormência das sementes, que, por alguma razão ainda desconhecida, inibe a germinação após a secagem das sementes (Kavati, 1992).

Lemos et al. (1988), trabalhando com quebra de dormência em sementes de $A$ squamosa L., obtiveram $75 \%$ de germinação quando submeteram as sementes a escarificação com lixa, eliminando assim a impermeabilidade do tegumento. Porém, Ferreira et al. (1997), estudando a curva de embebição de sementes de A. squamosa e de A. Cherimola Mill. X A. squamosa L. (atemóia), verificaram que as sementes de tais espécies não apresentam impedimentos físicos à entrada de água, descartandose assim a possibilidade de a dormência ser devida à impermeabilidade do tegumento.

De acordo com Esquinca et al. (1997), sementes de $A$. diversifolia apresentam dormência que pode ser quebrada com o uso de ácido giberélico. Para os autores, o mecanismo de dormência encontrado nesta espécie não é devido à dureza do tegumento ou à imaturidade, mas, sim, ao mecanismo de

1 (Trabalho 086/2000). Recebido: 05/06/2000. Aceito para publicação: 13/12/2001.

2 Prof Adjunto UNIOESTE/ Mal C. Rondon/PR; e-mail: giferreira@unioeste.br.

3 Bolsista PIBIC/ Institucional

4 Acadêmico do Curso de Agronomia 
dormência que eles relacionam como 'sobrevivência estacional'.

Weaver (1987) relata que a dormência pode ser resultado do balanço hormonal entre promotores e inibidores de crescimento. Da mesma forma, Bryant (1989) e Kigel \& Galili(1995) concordam que a quebra de dormência pode ser realizada pela mudança no balanço hormonal e que o ácido giberélico atua na promoção da germinação. Em sementes de cereais, as giberelinas ativam a síntese de enzimas que irão hidrolisar as reservas da semente, liberando energia para o crescimento do embrião (Taiz \& Zeiger, 1991), além de aumentar o alongamento celular, fazendo com que a radícula e a parte área possam desenvolver-se (Salisbury \& Ross, 1992).

Embora o uso de ácido giberélico seja uma das alternativas para quebra de dormência em sementes de diversas espécies, não foi possível detectar muitos trabalhos específicos para A. squamosa.

Pinto (1976), trabalhando com sementes de graviola (Annona muricata L.), obteve $82,1 \%$ de germinação, com o uso de $300 \mathrm{mg} . \mathrm{L}^{-1}$ de ácido giberélico, enquanto a testemunha apresentou 75,1\% de germinação. Hernández (1993) relata que o ácido giberélico usado em concentração de $100 \mathrm{mg} . \mathrm{L}^{-1}$ promoveu significativo aumento na germinação de Annona cherimola L. de $57,25 \%$ (testemunha) para 70,00\%.

Yousif et al. (1989), trabalhando com sementes de laranja'Azeda' (Citrus aurantium L.), obtiveram uma germinação de $83 \%$, com a aplicação de $50 \mathrm{mg} . \mathrm{L}^{-1} \mathrm{de} \mathrm{GA}_{3}$, por 6 horas. Leonel et al. (1994) também conseguiram bons resultados com a aplicação de 50 mg. $\mathrm{L}^{-1}$ em sementes de Citrus amblycarpa $(72 \%$ de germinação), porém os tratamentos com $100 \mathrm{mg} . \mathrm{L}^{-1}$ e $250 \mathrm{mg} . \mathrm{L}^{-1}$ não se mostraram benéficos, sendo inferiores à testemunha (68,75\% de germinação).

Segundo Ono et al. (1995), o tratamento de sementes de citrumelo 'Swingle' (Poncirus trifoliata x Citrus paradisi), com $250 \mathrm{mg} . \mathrm{L}^{-1}$ de $\mathrm{GA}_{3}$, por 24 horas, provocou uma menor porcentagem de germinação $(63,75 \%)$, quando comparada com a concentração de 50 mg.L $\mathrm{L}^{-1}(76 \%)$.

De acordo com Ferreira et al. (1998), a aplicação de 200 mg. $\mathrm{L}^{-1}$ de $\mathrm{GA}_{3}$ promoveu considerável aumento da germinação de sementes de Annona squamosa L. em condições de câmara de germinação com temperatura alternada entre 20 e $30^{\circ} \mathrm{C}$.

$\mathrm{O}$ objetivo deste trabalho foi verificar o efeito de diferentes concentrações de $\mathrm{GA}_{3}$ na germinação de sementes e na emergência de plântulas de fruta-do-conde (Anona squamosa L.) em diferentes embalagens, visando à produção de mudas.

\section{MATERIAL E MÉTODOS}

O Experimento foi conduzido em casa de vegetação e também no laboratório de sementes da UNIOESTE, câmpus de Marechal Cândido Rondon - PR.

Os frutos de Annona squamosa (fruta-do-conde), de onde foram extraídas as sementes para o experimento, apresentavam em média $7,5 \mathrm{~cm}$ de diâmetro, $8,0 \mathrm{~cm}$ de comprimento, $250 \mathrm{~g}$ e 65 sementes por fruto. As sementes foram extraídas manualmente, lavadas e colocadas para secar à sombra por uma semana.

$\mathrm{O}$ experimento foi instalado em delineamento experimental inteiramente casualizado. No laboratório, os tratamentos foram compostos pela embebição das sementes em sete concentrações de $\mathrm{GA}_{3}(0 ; 50 ; 100 ; 250 ; 500 ; 750$ e 1.000 mg. $L^{-1}$ de $\mathrm{GA}_{3}$ ), por 5 horas. Na casa de vegetação, os tratamentos foram constituídos pela embebição das sementes em sete concentrações de $\mathrm{GA}_{3}$ : 0; 50; 100; 250; 500; 750 e 1.000 mg.L-1 por 5 horas; e semeadas em dois tipos de embalagem: bandejas de isopor, com 72 células e dimensões de 12 × 34 x $67 \mathrm{~cm}$; e sacolas de polietileno, com capacidade de 0,5 L. Empregaram-se 4 repetições de 25 sementes cada, sendo empregado uma semente por sacola ou por célula da bandeja.

As sementes empregadas no experimento foram tratadas com captan a $0,5 \%$ logo após os tratamentos com o fitorregulador. No laboratório, realizou-se a semeadura em rolos de papel para germinação, os quais foram mantidos em câmara de germinação com temperatura alternada de $20-30^{\circ} \mathrm{C}$, no escuro. No campo, procedeu-se a semeadura nas sacolas de polietileno e bandejas de isopor, a uma profundidade de $3 \mathrm{~cm}$, contendo substrato comercial para mudas (GIOPLANTAII), as quais foram mantidas em casa de vegetação e temperatura média de $27^{\circ} \mathrm{C}$. O substrato era composto por vermiculita, fibra de coco e casca de arroz carbonizada.

As avaliações foram realizadas diariamente até o início da germinação e emergência de plântulas e, posteriormente, a cada 2 dias. Os parâmetros avaliados em laboratório constaram de porcentagem total de sementes germinadas (sementes que somente emitiram radícula ou se tornaram plântulas até a avaliação final do experimento), dormentes e mortas; porcentagem total de plântulas normais e anormais (porcentagens em relação ao valor total de sementes germinadas), comprimento das plântulas $(\mathrm{cm})$ e índice de velocidade de germinação (IVG), calculados no final do experimento. Os parâmetros avaliados no material do campo foram compostos pela porcentagem total de plântulas emergidas; índice de velocidade de emergência (IVE), altura das plântulas (cm) e número de folhas, obtidos no final do experimento. Os cálculos do IVG e IVE foram feitos de acordo com recomendações de Silva \& Nakagawa (1995). As avaliações foram encerradas no laboratório aos 33 dias e, no campo, aos 39 dias após a semeadura. Os dados obtidos foram submetidos a análise de variância e as médias comparadas pelo teste de Tukey, a 5\% de probabilidade, sendo que, no campo, os dados foram analisados em esquema fatorial 7 x 2 (concentrações x embalagens).Para o parâmetro número de folhas, o teste Tukey foi realizado a partir dos dados transformados em $\mathrm{V} x+0,5$, mas os valores apresentados nas tabelas de resultados são os originais.

\section{RESULTADOS E DISCUSSÃO}

Os dados referentes à germinação das sementes encontram-se na Tabela 1. Observa-se que o ácido giberélico, na concentração de $250 \mathrm{mg}$. $\mathrm{L}^{-1}$, proporcionou as melhores respostas para porcentagem de sementes germinadas e IVG, diferindo significativamente da testemunha. Além disso, este tratamento promoveu a menor porcentagem de sementes dormentes, diferindo do tratamento sem o uso de $\mathrm{GA}_{3}$ (testemunha).

Ao se analisar as porcentagens de plântulas normais e anormais e altura das plântulas, não se verificaram diferenças significativas entre os tratamentos. Embora 250 mg.L ${ }^{-1}$ de $\mathrm{GA}_{3}$ tenha promovido elevada porcentagem de plântulas anormais, 
TABELA 1 - Índice de velocidade de germinação (IVG), comprimento das plântulas, porcentagem total de sementes germinadas, dormentes e mortas, porcentagem de plântulas normais e anormais (laboratório). Marechal Cândido Rondon - PR, 2000.

\begin{tabular}{|c|c|c|c|c|c|c|c|}
\hline $\begin{array}{c}\mathrm{GA}_{3} \\
\left(\mathrm{mg} \cdot \mathrm{L}^{-1}\right)\end{array}$ & $\overline{\mathrm{IVG}}$ & $\begin{array}{c}\text { Comp.de } \\
\text { plântulas } \\
\text { (cm) }\end{array}$ & $\begin{array}{c}\% \\
\text { s ementes } \\
\text { germinadas }\end{array}$ & $\begin{array}{c}\% \\
\text { sementes } \\
\text { dormentes }\end{array}$ & $\begin{array}{c}\% \text { sementes } \\
\text { mortas }\end{array}$ & $\begin{array}{c}\text { \% plântulas } \\
\text { normais }\end{array}$ & $\begin{array}{c}\% \\
\text { plântu las } \\
\text { anormais }\end{array}$ \\
\hline 0 & $4,16^{1} \mathrm{~b}$ & $14,20 \mathrm{a}$ & $54,00 \mathrm{~b}$ & $45,00 \mathrm{a}$ & $1,00 \mathrm{a}$ & $50,00 \mathrm{a}$ & $3,00 \mathrm{ab}$ \\
\hline 50 & $4,35 \mathrm{~b}$ & $14,56 \mathrm{a}$ & $58,00 \mathrm{~b}$ & $39,00 \mathrm{ab}$ & $3,00 \mathrm{a}$ & $55,00 \mathrm{a}$ & $0,00 \mathrm{~b}$ \\
\hline 500 & $5,04 \mathrm{ab}$ & $13,34 \mathrm{a}$ & $65,00 \mathrm{ab}$ & $33,00 \mathrm{ab}$ & $2,00 \mathrm{a}$ & $58,00 \mathrm{a}$ & $7,00 \mathrm{ab}$ \\
\hline 750 & $4,96 \mathrm{ab}$ & $13,60 \mathrm{a}$ & $71,00 \mathrm{ab}$ & $26,00 \mathrm{~b}$ & $3,00 \mathrm{a}$ & $60,00 \mathrm{a}$ & $2,00 \mathrm{~b}$ \\
\hline 1.000 & $4,52 \mathrm{ab}$ & $14,46 \mathrm{a}$ & $68,00 \mathrm{ab}$ & $29,00 \mathrm{ab}$ & $3,00 \mathrm{a}$ & $61,00 \mathrm{a}$ & $1,00 \mathrm{~b}$ \\
\hline
\end{tabular}

(1) Médias seguidas das mesmas letras minúsculas, nas colunas, não diferem entre si, pelo teste de Tukey a 5\%.

TABELA 2 - Porcentagem total de plântulas emergidas e índice de velocidade de emergência de plântulas (IVE), no campo. Combinações entre concentrações e embalagens. Marechal Cândido Rondon - PR, 2000.

\begin{tabular}{|c|c|c|c|c|c|c|}
\hline \multirow{2}{*}{$\begin{array}{c}\mathrm{GA}_{3} \\
\left(\mathrm{mg} \cdot \mathrm{L}^{-1}\right)\end{array}$} & \multicolumn{2}{|c|}{$\%$ de Emergência } & \multirow[t]{2}{*}{ M édia } & \multicolumn{2}{|c|}{ IVE } & \multirow[t]{2}{*}{ M édia } \\
\hline & Bandejas & Sacolas & & Bandejas & Sacolas & \\
\hline 0 & $44,00^{1} \mathrm{~A} \mathrm{a}$ & $44,00 \mathrm{~A} \mathrm{ab}$ & $44,00 \mathrm{a}$ & $1,78 \mathrm{~A} \mathrm{a}$ & $1,60 \mathrm{~A} \mathrm{a}$ & $1,69 \mathrm{a}$ \\
\hline 100 & $54,00 \mathrm{~A} \mathrm{a}$ & $55,00 \mathrm{~A} \mathrm{a}$ & $54,50 \mathrm{a}$ & $2,14 \mathrm{~A} \mathrm{a}$ & $2,01 \mathrm{~A} \mathrm{a}$ & $2,08 \mathrm{a}$ \\
\hline 250 & $63,00 \mathrm{~A} \mathrm{a}$ & $30,00 \mathrm{Bb}$ & $46,50 \mathrm{a}$ & $2,58 \mathrm{~A} \mathrm{a}$ & $1,13 \mathrm{Ba}$ & $1,86 \mathrm{a}$ \\
\hline 750 & $49,00 \mathrm{~A} \mathrm{a}$ & $54,00 \mathrm{~A} \mathrm{a}$ & $51,50 \mathrm{a}$ & $1,85 \mathrm{~A} \mathrm{a}$ & $1,85 \mathrm{~A} \mathrm{a}$ & $1,85 \mathrm{a}$ \\
\hline 1.000 & $54,00 \mathrm{~A} \mathrm{a}$ & $45,00 \mathrm{~A} \mathrm{ab}$ & $49,50 \mathrm{a}$ & $2,28 \mathrm{~A} \mathrm{a}$ & $1,63 \mathrm{Ba}$ & $1,95 \mathrm{a}$ \\
\hline M éd ias & $50,14 \mathrm{~A}$ & $44,57 \mathrm{~A}$ & & $2,02 \mathrm{~A}$ & $1,62 \mathrm{~B}$ & \\
\hline C.V. $(\%)$ & \multicolumn{2}{|c|}{18,10} & \multicolumn{3}{|c|}{24,28} & \\
\hline
\end{tabular}

(1) Médias seguidas das mesmas letras maiúsculas, nas linhas, e das letras minúsculas, nas colunas, não diferem entre si, pelo teste de Tukey a 5\%.

TABELA 3 - Altura de plântulas emergidas e número de folhas (campo). Combinações entre concentrações e embalagens. Marechal Cândido Rondon - PR, 2000.

\begin{tabular}{|c|c|c|c|c|c|c|}
\hline \multirow{2}{*}{$\begin{array}{c}\mathrm{GA}_{3} \\
\left(\mathrm{mg} \cdot \mathrm{L}^{-1}\right)\end{array}$} & \multicolumn{2}{|c|}{$\overline{\text { A ltura }(\mathrm{cm})}$} & \multirow[t]{2}{*}{ Média } & \multicolumn{2}{|c|}{$\mathrm{N}^{\circ}$. de folhas } & \multirow[t]{2}{*}{ Média } \\
\hline & Bandejas & Sacolas & & Bandejas & Sacolas & \\
\hline 0 & $5,12^{1} \mathrm{Aa}$ & $6,07 \mathrm{~A} \mathrm{a}$ & $5,59 \mathrm{a}$ & $3,24 \mathrm{~A} \mathrm{a}$ & $3,86 \mathrm{~A} \mathrm{a}$ & $3,55 \mathrm{a}$ \\
\hline 50 & $5,21 \mathrm{~A} \mathrm{a}$ & $5,69 \mathrm{Aa}$ & $5,45 \mathrm{a}$ & $3,15 \mathrm{~A} \mathrm{a}$ & $3,25 \mathrm{Aa}$ & $3,21 \mathrm{a}$ \\
\hline 100 & $4,70 \mathrm{Aa}$ & $6,01 \mathrm{Aa}$ & $5,36 \mathrm{a}$ & $3,03 \mathrm{~A} \mathrm{a}$ & $3,62 \mathrm{~A} \mathrm{a}$ & $3,33 \mathrm{a}$ \\
\hline 250 & $5,05 \mathrm{~A} \mathrm{a}$ & $5,57 \mathrm{Aa}$ & $5,31 \mathrm{a}$ & $3,21 \mathrm{~A} \mathrm{a}$ & $3,37 \mathrm{~A} \mathrm{a}$ & $3,29 \mathrm{a}$ \\
\hline 500 & $4,89 \mathrm{~A} \mathrm{a}$ & $5,86 \mathrm{~A} \mathrm{a}$ & $5,37 \mathrm{a}$ & $3,14 \mathrm{~A} \mathrm{a}$ & $3,46 \mathrm{~A} \mathrm{a}$ & $3,30 \mathrm{a}$ \\
\hline 750 & $5,00 \mathrm{~A} \mathrm{a}$ & $6,20 \mathrm{Aa}$ & $5,60 \mathrm{a}$ & $3,38 \mathrm{~A} \mathrm{a}$ & $3,54 \mathrm{Aa}$ & $3,46 \mathrm{a}$ \\
\hline 1.000 & $5,16 \mathrm{~A} \mathrm{a}$ & $5,93 \mathrm{~A} \mathrm{a}$ & $5,54 \mathrm{a}$ & $3,28 \mathrm{~A} \mathrm{a}$ & 3,39 A a & $3,33 \mathrm{a}$ \\
\hline M ÉDIA S & $5,02 \mathrm{~B}$ & $5,90 \mathrm{~A}$ & & $3,21 \mathrm{~B}$ & $3,50 \mathrm{~A}$ & \\
\hline
\end{tabular}

(1) Médias seguidas das mesmas letras maiúsculas, nas linhas, e das letras minúsculas, nas colunas, não diferem entre si, pelo teste de Tukey a 5\%. 
sendo o pior resultado, esta concentração não interferiu na porcentagem de plântulas normais de forma significativa (Tabela 1).

As respostas positivas quanto ao uso do ácido giberélico em sementes estão de acordo com citações de Weaver (1987), Bryant (1989), Taiz \& Zeiger (1991), Salisbury \& Ross (1992) e Kigel \& Galili (1995). Além disso, Pinto (1976) e Ferreira et al. (1998) também obtiveram aumento na porcentagem de germinação de sementes do gênero Annona com o uso de concentrações semelhantes de $\mathrm{GA}_{3}$, sendo $300 \mathrm{mg} . \mathrm{L}^{-1}$ para $A$. muricata e $200 \mathrm{mg} . \mathrm{L}^{-1}$ para $A$. squamosa, respectivamente. Segundo Hernández (1993), 100 mg.L-1 de $\mathrm{GA}_{3}$ foram suficientes para aumentar significativamente a porcentagem de germinação de Annona cherimola. Neste experimento, tal concentração não diferiu de $250 \mathrm{mg} . \mathrm{L}^{-1}$ para porcentagem de germinação e IVG; no entanto, foi semelhante à testemunha, que apresentou os piores resultados.

Na casa de vegetação, a aplicação de GA, nas sementes de fruta-do-conde, não influenciou na porcentagem de emergência (Tabela 2), pois não ocorreu diferença entre as médias de bandeja e sacola. O tratamento com $250 \mathrm{mg} . \mathrm{L}^{-1} \mathrm{de} \mathrm{GA}_{3}$ promoveu a menor porcentagem de emergência $(30,00 \%)$ nas sacolas, embora não tenha diferido significativamente dos tratamentos 50,500 e 1.000 mg. $\mathrm{L}^{-1}$ e da testemunha $(32,00 \%, 52,00 \%, 45,00 \%$ e $44,00 \%$, respectivamente). Estes dados assemelham-se aos relatados por Leonel et al. (1994) e Ono et al. (1995) com sementes de Citrus amblycarpa e citrumelo 'Swingle'. Porém, cabe salientar que Ono et al. (1995) mantiveram as sementes embebidas por 24 horas, o que pode ter afetado a germinação; além disso, os autores citados obtiveram bons resultados com concentrações menores, o que, neste experimento, não foi verificado.

Em relação ao índice de velocidade de emergência das plântulas em casa de vegetação, a aplicação de $\mathrm{GA}_{3}$ não $\mathrm{o}$ influenciou, tanto nas bandejas como nas sacolas (Tabela 2). Porém, entre as médias, a bandeja foi significativamente superior à sacola, promovendo maior velocidade de emergência.

Considerando-se o desenvolvimento inicial das mudas, verifica-se que não ocorreram diferenças significativas entre os tratamentos com $\mathrm{GA}_{3}$ para os parâmetros estudados, nem interações entre os fatores (Tabela 3). Mas há diferenças entre as médias das embalagens, sendo a sacola superior à bandeja nos parâmetros avaliados. Pode-se observar que, embora a bandeja tenha favorecido anteriormente o IVE (Tabela 2), esta diferença é anulada logo em seguida, pois o sistema radicular da espécie desenvolve-se muito rapidamente, necessitando de espaço que não existiu nas bandejas e, conseqüentemente, as plântulas desenvolveram-se menos que nas sacolas (Tabela 3 ).

\section{CONCLUSÃO}

Nas condições em que foi conduzido o presente trabalho, pode-se concluir que a aplicação de $\mathrm{GA}_{3}$ influenciou positivamente a germinação de sementes de A. squamosa L., porém não afetou a emergência das plântulas nas embalagens em casa de vegetação.

\section{REFERÊNCIAS BIBLIOGRÁFICAS}

BRYANT, J.A. Fisiologia das sementes. São Paulo: Editora Pedagógica Universitária, 1989. 85p.

ESQUINCA, A.R.G.; MOCTEZUMA, J.G.A.; PÉREZ, G.M.P. Duración de la latencia e importancia de la cubierta dura y de la inmadurez anatómica, en la inhibición de la germinación de la papausa blanca (Annona diversifolia Saff., Magnoliade, Annonaceae) Investigación, ciencias y artes en Chiapas, México, v. p.37-44, 1997.

FERREIRA, G., CEREDA,E., SILVA, C.P., CUNHA, R.J.P., CATANEO, A. Imbibition study of sugar apple (Annona squamosa L.) and atemoya (Annona squamosa L. X A. Cherimola Mill.) sedes. In: CONGRESO INTERNACIONAL DE ANONACEAS, 1., 1997, Chapingo, México. Memorias...Chapingo, México: Universidad Autónoma Chapingo, 1997. p.210-224.

FERREIRA, G.; SILVA, C. P.; CEREDA, E.; PEDRAS, J. F. Efeito do ácido giberélico $\left(\mathrm{GA}_{3}\right)$ na germinação de sementes de frutado-conde (Annona squamosa L.), In: CONGRESSO NACIONAL DE BOTÂANICA, 49. 1998, Salvador. Anais .... Salvador: Sociedade de Botânica do Brasil, 1998. p.186-7.

HERNÁNDEZ, L.V. La reproducción sexual y multiplicación vegetativa de la annonaceas. Xalapa: Universidad Veracruzana, 1993.35p.

KAVATI, R. O cultivo da atemóia. In: DONADIO, L. C.; MARTINS, A. B. G.; VALENTE, J. P. (Ed.) Fruticultura tropical. Jaboticabal: FUNEP, 1992.p.39-70.

KIGEL, J.; GALILI, G. Seed development and germination. 2. ed. New York: Plenum Press, 1995. 853p.

LEONEL, S.; MODESTO, J. C.; RODRIGUES, J. D. Influência de fitorreguladores e nitrato de potássio na germinação de sementes e no crescimento de porta-enxertos de Citrus amblycarpa. Science in Agricultura., V. 51, p. 252-259, 1994.

ONO, E. O.; LEONEL S.; RODRIGUES, J. D. Efeitos de fitorreguladores na germinação de sementes de citrumelo 'Swingle'. Semina Ci. Agr. v. 16, n. 1, p. 47-50, 1995.

PINTO, A.C.Q. Influência de hormônio sobre o poder germinativo de sementes de graviola. CONGRESSO BRASILEIRO DE FRUTICULTURA, 3., 1975, Rio de Janeiro. Anais...Rio de Janeiro: Sociedade Brasileira de Fruticultura, 1976. P.415-420.

SALISBURY, F.B., ROSS, C.W. Plant physiology. 4. ed. California: Wadsworth, 1992, 682p.

SILVA, J.B.C., NAKAGAWA, J. Estudo de fórmulas para cálculos de velocidade de germinação. Informativo ABRATES, Brásilia, v.5, n.1, p.62-73, 1995.

TAIZ, L., ZEIGER, E. Plant physiology. California: The Benjamin/ 
Cummings Publishing Company, 1991. 565p.

WEAVER, R.J. Reguladores del crecimiento de las plantas en la agricultura. 5. ed. Mexico: Trillas, 1987. 622p.
YOUSIF, Y. H., HASSAN, K., AL-SAADOON, H. S. Effect of giberellic acid on germination of sour orange seeds and their growth in ten soils mixes, Annals. Of Agricultural. Science, v.34,p.1139-49, 1989. 